Carey, M. (2019) 'Some ethical limitations of privatising and marketizing social care and social work provision in England for children and young people' Ethics and Social Welfare Online Access: March 1th

Prof. Malcolm Carey

Faculty of Health and Social Care

University of Chester

Martin Building

Crab Lane

Fearnhead

Warrington

WA2 0DB

m.carey@chester.ac.uk 


\section{Some ethical limitations of privatising and marketizing social care and social work provi- sion in England for children and young people}

\section{Abstract}

This article analyses the negative ethical impact of privatisation, alongside the ongoing marketisation of social care and social work provision for children and young people in England. It critically appraises the implications of a market-based formal social care system, which includes the risk-averse and often detached role of social workers within ever more fragmented sectors of care. Analysis begins with a discussion of background policy and context. The tendency towards 'service user' objectification and commodification are then detailed, followed by a discussion of the limiting of choice for service users. Service and social fragmentation, and the often severely restricted 'life chances' of many children and young people in care, are then deliberated. The concluding discussion reiterates the moral implications of marketisation in relation to ethical frameworks, including those associated with autonomy, informed choice, social exclusion and social justice. The tendency towards children increasingly being utilised as a means to an end within business-orientated sectors of care is highlighted, alongside ethical questions asked about the State's purpose in providing a community of support.

Keywords: children in care; privatisation; commodification; fragmentation; reduced life chances 


\section{Ethical limitations of privatising and marketizing social care and social work provision in England for children and young people}

\section{Introduction}

In recent years there has continued a substantial increase in private sector ownership of social care services for children and young people within England and some other parts of the United Kingdom (UK). For example, in England from between 2000/01 to 2012/13, there was a 342 per cent increase in the total proportion of foster care days purchased from the private sector by local authorities. Relative market dominance has also formed in some key sectors. For example, three quarters of foster care placements commissioned in England are now provided by 'an oligopoly of a few, large, Independent Fostering Providers' (LaingBuisson, 2016: 121). Moreover, smaller providers - such as social enterprises or voluntary organisations, which successive governments have identified as ideal providers - have largely been 'forced out' (Williams, 2012).

In tandem with service provision, other crucial roles previously led by local authorities within Local Government have continued to be exposed to rapid marketisation. This includes core professional social work roles such as assessments, decision making about care proceedings within courts - including to remove children from families - and judgements made about subsequent care. Such policy initiatives remain relatively unique in an international context, since many other nation-states have tended to keep most such responsibilities and powers chiefly in the control of the State (Clarke, 1996; Harris, 2003; Jordan and Drakeford, 2012).

This article takes a critical overview of some ethical and moral implications attached to privatisation and marketisation within English formal childcare services and provision. It highlights tensions and challenges for children and social workers amidst the development of an ever 
more fragmented, economically deterministic, and market-based social care system. The article is presented in five key sections beginning with a discussion of policy background and context. This is followed by details of a proposed tendency towards 'service user' commodification and the limiting of choice, service and socially determined fragmentation, and the significant reducing of 'life chances' of many children and young people. The concluding discussion reiterates the ethical limitations of marketisation discussed earlier, including those relating to informed choice and social exclusion. By briefly drawing from Aristotle, wider questions are also asked about the current compromised role of the State in providing care to children and young people.

\section{Contextualising the rise of private-sector social care for children and young people in}

\section{England}

The expansion of private sector provision within social care in England and some other parts of the UK has a relatively long history. Despite some differences in the extent and patterns of related policies, marketisation has still retained considerable impact across the UK. The rapid growth of private sector adult residential and nursing care homes throughout the 1980s, which previously had been almost exclusively owned and run by local authorities, began an ambitious political and cultural process (Harris, 2003; Scourfield, 2007; Williams, 2012). This was partially initiated from strains evident throughout the development of the Keynesian Welfare State, and wider neoliberal ideological counternarratives: which reiterated anxieties about inefficient and expensive public services, State-owned monopoly service provision and widely publicised systematic 'failures' by social workers, in order to pursue market-based policies within sectors such as social care (Lewis, 1998; Harris, 2003; Garrett, 2018). The gradual ideological switch to prioritising consumerism and eclectic service provision challenged public sector and welfare 
professional dominance, whilst promoting competition, 'service user' engagement, choice, participation and, eventually, the centrality of civic responsibilities and community assets (Rose, 1996; Webb, 2006; Cowden and Singh, 2007; Fenwick and McMillan, 2012).

By 1981, Compulsory Competitive Tendering for services such as refuse and waste collection became mandatory for local authorities, and such centrally prescribed deregulation spread quickly to other sectors (Petrie, 2015). Within adult social care, for example, local authorities were compelled to compete for contracts with voluntary and private sector providers under the National Health Service and Community Care (NHS and CC) Act 1990 (Lewis and Glennerster, 1996; Jordan and Drakeford, 2012). In principle, at least, the formal care of children was intended to be much more restrained. Although the Children Act (1989) had again sought to promote competition, there were important distinctions made by policy makers. This included priority being given to the voluntary sector to provide more services. However, as Petrie (2015: 277) highlights, legal differences were reinterpreted at street-level and beyond to still favour the growth of private sector services, as many local authorities 'simply organised children's services along the same lines [as adult care] resulting in an increase in the role of the private sector'.

Despite altering direction and the language used, the New Labour government of 1997 largely strengthened this position further. Compulsory Competitive Tendering, for example, was replaced with Best Value in 1999, and then Social Value in 2012. Each policy reform promoted the further rescinding of State-owned care for children and young people, alongside the continued growth of the private sector. These initiatives were also more ideologically comprehensive than policies attempted by previous Conservative governments. For example, they helped to reinforce an apparent need to promote an objective 'evidence base' of service impact and stimulate more choice and participation. Much greater privatization ensued alongside a related 'Third Way' inspired push for elevated community and civic engagement, personal autonomy 
and family responsibilities (Rose, 1996; Jordan and Drakeford, 2012; Garrett, 2018). Other market-based outcomes included the proliferation of 'minimum wage' employment for social care employees, and the raising of eligibility criterion for social care support services, with the latter closely facilitated by social workers (Clarke, 1996; Jordan and Drakeford, 2012; Harris, 2003). Such cumulative market-infused initiatives - which have consistently included rationing, risk-aversion, surveillance and punitive interventions as an established norm in social care provision - have intensified further under subsequent Coalition and Conservative governments, including related 'austerity' policies (Jordan and Drakeford, 2012; Baines, 2016; Garrett, 2018).

A rapid exchange of ownership has taken place between public sector 'monopolies' and private sector businesses for social care services for children and young people. For example, from a negligible amount of ownership during the 1980s in England, the private sector has increased its share of the 'market' of residential homes for children to 65 per cent by 2011; with State owned homes shrinking from 61 per cent to 20 per cent between 2001 and 2017 (LaingBuisson, 2016; Department for Education, 2017). Although initially playing a more significant role, the voluntary sector has struggled to cope with reduced local authority financing. Due to a need to cut overhead costs - especially regarding labour - smaller charities, in particular, have retreated from ever more capricious and impersonal quasi-markets. In relation, most voluntary sector organisations rely upon donations and a positive image, and this source of income can be negatively affected by any soiled reputation associated with inconsistent care, low wages and poor employment rights for staff. Much of the void left by the shrinking of public and retreat of voluntary sectors has been filled by private equity firms, who have chiefly followed a venture capitalist model of aggressively reducing costs despite often making significant profits (Williams, 2012: 13-33). Although claiming to promote competition and move away from 'monopolies' of State-centred care, two of England's three biggest private sector providers of foster 
care placements are now owned by private equity firms. However, as Williams (2012: 12) notes, their 'waters seem to be in perpetual motion' since takeovers and the offloading of assets continue along with poor employment rights for ever more transient staff.

\section{Commodifying children within care and limiting choice}

The promotion of a 'social work business' led to the construction of 'care packages' for rigorously assessed and categorised 'service users'. This entailed an ideological shift away from a model of welfare based on Fabian ideals - to, in principle, promote community-based rights, equity and citizenship - towards more restricted consumer-led notions of autonomy and rational choice as part of service transactions and risk-based calculations (Webb, 2006; Kemshall, 2010). Relationship-based approaches within social work were subsequently marginalised and have since all but disappeared. This is alongside increased priority given to interventions based around risk-aversion, empirical evidence and a managerial focus on audit, form-filling, measurement and following procedure (Howe, 1998; Ferguson, 2017). Indeed, Parton (2008: 253) maintain that despite minimal interventions, modern social work for children and families now largely operates 'less on the terrain of the 'social' and more within the jurisdiction of the 'informational"'. This model would appear to fit with Foucault's (1991) earlier argument that welfare professional employment processes increasingly centre on the collection and processing of (surveillance-related) information - alongside the dissemination of dominant norms - rather than the provision of altruistic welfare or support.

To some commentators the proliferation of bureaucratic assessments and contracts has meant that many of the substantive needs of children or young adults have become neglected. Instead children are mechanically processed, quantified and scientifically evaluated according to ranked needs. Such care managed interventions through market-based 'technologies of care' including assessments of need and service evaluations lead to 'service users' gaining a market 
exchange value among competing service providers. Multifarious procedures within quasimarket 1 fields effectively reconstitute children and other service users as commodified objects, dehumanised or even lost within administrative storms of contracts, procedures, assessments, care plans and negotiations between local authorities, welfare professionals, service purchasers and providers (for example, Carey, 2003; Petrie, 2010; Humphris and Sigona, 2017). Associated 'quasi-business' principles have included an institutional drive to embed market-based idioms such as prioritising control, predictability, calculability, efficiencies and cost-savings (Coleman and Harris, 2008). In addition, instrumental forms of acute rationality lead to the development of 'actuarial risk social work', in which pressures to control and formalise costs and social risks during fleeting case work with young service users become conflated with recognised needs, leading to expert interventions becoming ever more superficial, reductive or crude (Webb, 2006: 6).

Further problems persist when reconstituting children and young service users as quasi-consumers. When requiring personal support or care at short-notice, no meaningful informed choice is made available for children in need, since adults as professionals and service providers make any core decisions in their respective service-purchaser and technical gatekeeping role. This conjures up some enduring ethical concerns generated by markets. For example, the limiting of purposeful autonomy for 'service users' due to significant power disparities generated between resource-controlling and legally empowered professionals and dependent 'clients'. As Estes et al, (2003: 92-93) suggest, within market-based welfare and professional discursive arenas, there is rarely much thought given during interactions to 'the power environment that shapes ethical discourse itself', which is invariably unequal with regard factors such as any institutional desire for efficiency or cost containment, alongside the extensive knowledge required to make meaningful informed decisions and rational choices. Other influential factors, such as the relative emotional and psychological immaturity of young people 
again further reduces their autonomy and capacity for informed choice, which can promote further exclusion and commodification. Such powerful inequalities can quickly become more intense with associate factors such as a child having a learning disability, sensory impairment or not being fluent in the English language or culture (Young and colleagues, 2006). Jorgensen and colleagues (2009), for example, argue that from an ethical perspective, no substantive autonomy or meaningful choice persists for patients or other welfare customers without the provision of adequate support and typically detailed information. This includes any insight provided about the benefits and drawbacks of receiving services or treatments within a care setting (see also Young and colleagues, 2006; Agnew and Jorgensen, 2012).

Within markets, services can often struggle to meet more specific needs - since to appease shareholders, as well as function and survive within a challenging business environment, there have to be degrees of standardisation and commonality to achieve 'economies of scale' in order to maintain economic viability. As well as again limiting choice, such tensions not uncommonly cause problems of quality and suitability for many children. For example, in 2012 there were 5,000 children in residential care in England costing around $£ 200,000$ per annum. Despite high overall costs, there were nevertheless typically 'low standards of care' provided according to the Office for Standards in Educations (Ofsted). Requirements to meet broad-based government targets in brief time frames has also merited a culture of 'short-termism' within professional social care (and other sector such as Health and Education), that counters the need to provide long-term stability for children and young adults, and which can again undermine the principles of choice (Williams, 2012: 13).

As discussed, the fundamental ethical principle of informed choice within social work is typically strongly influenced by the complexity of individual needs, including those relating to capacity. If making choices, Morris (2005: 25) argues that disabled children frequently have a greater need to be supported and consulted emotionally by professionals such as social workers. 
Morris, however, adds that such roles have tended to be undermined since the advent of markets due to the prevalence of performance related targets, high levels of bureaucracy and limited resources. Such outcomes can lead to a high turnover of staff within local authorities, which can also fuel further prejudice. For example, a number of professionals with limited available time can prioritise physical safety for children with learning disabilities, rather than the meeting of social, cultural or identity related needs (Thomas, 2007). Young and others (2009: 5-9) survey of 57 local authorities providing statutory social work to deaf children following marketbased reforms, highlighted a lack of 'specific attention' given to deaf children or families' basic rights. This persisted in tandem with 'poor recognition of need and provision of assessment'.

More recently, Humphris and Sigona (2017: 6-15) draw from mixed methodological research to highlight how financial austerity within the UK alongside intense pressures to manage shrinking budgets now almost exclusively determines the care provided to unaccompanied children. This has included a tension between the state enthusiastically wishing to maintain a monopoly on 'policing borders' despite paradoxically delegating it's authority by eagerly outsourcing many associate services from government administrative agencies to private and nonstate actors. One important consequence is that frequent service outsourcing and over reliance upon out-of-county care placements are being used ever more by local authorities to distance themselves from their statutory and legal responsibilities towards unaccompanied asylumseeking children. The authors argue that the principle of meeting the 'best interests' of children enshrined in national and international law has been reconfigured and neglected through three inter-related processes. First, the dominant role of private sector service providers has helped to widen any moral distance between the goals and priorities of increasingly business-centred managers in local authorities and front-line social workers. Second, an economic and ideological push for efficiency savings leads to asylum seeking children being moved geographically to localities where the cost of their care is cheaper (so called "pinball kids"), which again leads 
to the undermining of their capacity to access appropriate support. In addition, newly qualified social workers are prioritised in recruitment drives to save money, despite more experienced employees often being more suited to meeting many children's more complex needs. Finally, ongoing restructuring and mainstreaming of services within local authorities helps to again limit and undermine the substantive expertise required to meet any such children's complex needs. Consequences can include an increased risk of neglect or abuse for children in unfamiliar geographical areas. The authors add that together such inter-related political dynamics and outcomes now pose significant risks to asylum-seeking children, whilst limiting the spaces for resistance previously available to front-line social workers.

\section{Fragmenting care within complex societies}

Another important consequence of privatisation within social work has been the significant increase in the proportion of service providers in core sectors such as residential and foster care. For example, as of March 2017 in England, private organisations ran a total of 1,538 (72 per cent) children and young people's residential care homes, voluntary organisations 164 (8 per cent), and local authorities 434 (20 per cent). A small majority of providers own one or two care homes, yet the largest twenty service providers own 37 per cent of the total number of care homes for children (LaingBuisson, 2016: 10; Department for Education, 2017). Despite many hundreds of care homes in England, there persist significant geographical and service inconsistencies. For example, the North West of England has a total of 514 homes serving a population of 6.9 million ( 1 home per 13,424 people), London 130 homes serving more than 7.8 million people ( 1 per 60,000 people) and Rochdale 41 care homes serving a population of just over 200,000 (1 per 4,878 people) (Department for Education, 2017). Rather than reflect local demand or children's specific needs, the location of care homes is more likely to be influenced by factors such as the cost of housing stock in a local area, and the availability or otherwise of lower-cost properties. As discussed earlier, to reduce costs to local authorities many children 
are subsequently relocated far away from their original place of residence prior to entering care. This commonly detaches children or young people from established familial and social ties, thus adding to their sense of dislocation, isolation or stress. Emotionally and psychologically this is likely to be deeply traumatic and can pose significant risks, including potentially undermining their capacity to develop and learn, or making children more vulnerable to further neglect or abuse. For example, in recent years some children in residential care have been targeted and recruited by organised street gangs to engage in so-called 'County Lines' drug dealing. There have also been historic cases of sexual abuse in specific areas such as Rotherham with a high proportion of care homes, suggesting specific areas may be targeted by criminals (Humphris and Sigona, 2017; British Broadcasting Corporation, 2018).

Multiple providers in sectors such as residential care generates a number of practical and ethical problems for social workers seeking to provide the best possible care for children or young people. Alongside uncertainty about ownership and the quality or consistency of available staffing and support, the overriding principle of maximising 'surplus value' as profit can invariably impinge upon the quality of day to day provision. For example, the cost of furnishing, food, accommodation, and other overheads may be reduced by some commercial owners (Scourfield, 2007; Williams, 2012). Clarke (1996: 58) has previously stressed the financial cost of coordinating or regulating different support services and service providers. 'Disjointed purchasing' can be deeply inefficient for the State as principle funder of social care and welfare, and undermine its power to commission 'in such a way as to drive standards up'. This includes to deliver 'social, environmental and economic value'. Instead, local authorities and local government departments have tended to move cost-burdens around while incurring heavy financial costs within often inefficient systems of financing and service purchasing (Williams, 2012: 6). Another problem remains the complexity of contracts and sub-contracts which remain a key part of quasi-market financing and regulation, with profits typically taken at different levels. 
This effectively turns excessive public money into private wealth when it could instead be reinvested in services, and ultimately 'exacerbates the sort of inequalities that public services are trying to tackle' (Williams, 2012: 5). Alongside the prevalence of changing ownership, this often leads to further uncertainty and waste, which has a negative impact upon the levels of consistent support available to young residents. Another example of excessive service-led costs and waste through contracting has recently been provided by Jones (2015: 454-455). He details the advent of the 'reclaiming social work' model, and subsequent growth of Morning Lane Associates in supporting a new template for organising social work management and delivery:

When (Alan) Wood was director of children's services in Hackney, one of his senior managers was Isabelle Trowler. She, along with Steve Goodman... developed the 'reclaiming social work' model of small units led by a consultant social worker which assessed and worked with children and families. Goodman and Trowler left Hackney Council and established a company, Morning Lane Associates to promote and market what became known as the 'Hackney model', selling consultancy to local authorities that were looking to adopt the model. Cambridgeshire County Council, for example, between December 2010 and January 2013 paid Morning Lane Associates £474, 750 for assistance in introducing the 'Hackney model' in Cambridgeshire...In 2014 [a further] $£ 400,000$ was awarded through the [Government funded Children’s Social Care] Innovation Fund to Morning Lane Associates (and five partner councils) to promote 'reclaiming social work'.

Davies (2009) and Granter (2019) highlight that when extensive commissioning, procurement, outsourcing and contracting emerge within public sector welfare regimes, there invariably persists a higher risk of opportunism, greed and corruption emerging: which can again further arouse considerable market-based inefficiencies, as well as significantly undermine 'lay' or professional moral norms. This can also quickly enable a 'society of rackets' in which often 
hidden networks of influence link political and corporate powers 'into a collection of cliques' that operationalize power outside legislative channels - or subvert them - to serve business related needs, and undermine the public interest including at times 'in the more conventional sense of malfeasance and criminality' (Granter, 2019: 69). For social work interpreted from a virtue ethics perspective, this devious political culture clearly counters the core principles of honesty and integrity. Moreover, this can also lead to an almost inbuilt tendency to generate structural inefficiencies, including business generated which may not be essential or necessarily beneficial for welfare recipients, but instead serves to meet the financial needs of potentially opportunistic service providers. Despite higher payments and overall costs, there is limited evidence to suggest that subsequent support services for children within social care have improved the level of care available (for example, Sellick, 2011). Indeed Williams (2012: 5) maintains that when many private sector service providers fail to deliver quality services - including positive outcomes for children or young adults - they 'often go on to win more business'. This is typically due to a capacity to establish market power and dominance, or because complex business arrangements alongside limited available information due to commercial confidentiality, make it 'impossible to hold many providers properly to account'.

For children and young people requiring social work support it is not merely the provision of core services which have been affected by privatisation. The rise in the proportion of private contract 'agency' employees since the 1990s has meant that the number of permanently employed qualified social workers retained by local authorities over a long period has declined. Among other consequences, this trend has led to the increasing cost of contingent professional labour. For example, annual spending in the UK on agency employees within social work increased from a negligible level throughout the 1970 s and 1980 s to $£ 180 \mathrm{~m}$ in 2012 and $£ 356 \mathrm{~m}$ in 2016-17 (Holt and Greenwood, 2017). In child care, agency employees chiefly assess and purchase services for local authorities, and are used to provide short-term cover for permanent 
staff, or fulfil other specific projects and roles to 'keep the show on the road' (Cornes and others, 2010: 63-64). However, substantive familiarity with organisational procedures and policies, casework and specific children, families or local needs and services, may only become adequate at a point when a contract ends. Such flexible yet fragmented 'locum' work is therefore unlikely to provide the required familiarity and stability for younger people.

Such outcomes again suggest evidence of an innate tendency towards objectification and commodification for service users within social care markets. This propensity counters a number of core ethical principles and duties. For example, in the Formulae of Humanity, Kant advocated the moral rule of not treating people as 'a means to an end', itself a crucial principle attached to all professional social work codes of ethics. As Kerstein (2009: 163) notes, this binding and almost transcendental moral dictate maintains that if an agent 'treats another merely as a means, then his action is morally impermissible'. Yet, in prioritising principles such as the importance of financial cost to care - including through economic tenets such as competition and efficiency - as well as numerous other related outcomes such as the promotion of much more transient professional labour, the likelihood of being reduced to a means invariably increases for service users. Other perspectives which are more explicit in their support of meaningful, consistent and compassionate care - notably the ethics of care or virtue ethics - are placed under further strain within social care markets that are so tightly held within a business discourse.

Wider social trends can add further pressures to any volatility and risk for children and young adults. For example, sociologists including Giddens (1991) and Lash (2007) have for some time stressed how late modern societies continue to become much more socially and culturally intricate, unpredictable and fluid. The development of more complex social relationships alongside different expectations, changing values or norms, and increased reliance on technology, can all have influence. The advent of changes in family forms, globalisation, increased 
migrations, the breakdown of traditional communities, among numerous other examples, can again all generate more uncertainties and potential risks. Such often unpredictable trends, some of which can alter in relatively short-time frames, can be further strained through excessive marketization, service fragmentation, welfare retrenchment and policy-led reforms, and add further pressures upon social works capacity to meaningfully support children or other potentially vulnerable groups (Carey and Foster, 2013).

\section{Reduced life chances of children and young people in care}

The numbers of children entering local authority care in England and Wales has continued to increase. There was a total of 72,670 children in care in 2017 in contrast to less than 49,000 in 1994, with an average of 90 children or young people taken into care each day in 2017. Despite a reduction in available resources, this is highest reported proportion of children being brought into formal care on record (Richardson, 2017; Department for Education, 2017). In comparison to their peers not in care, many children within the formal care system experience significantly reduced 'life chances'. This is especially in relation to regularly facing extremely limited education and employment opportunities, a much greater likelihood of developing drug or alcoholrelated addictions as adults, or being diagnosed with a mental health condition, becoming sex workers, long-term unemployed or entering the criminal justice system and prison (Sebba and others, 2015; Office for National Statistics, 2016; Datta and others, 2017). In 2015, 14 per cent of children in care in England achieved five or more GCSE passes, in comparison to 53 per cent of children in the general population. Moreover, 61 per cent of children in care was diagnosed as having a special education need, in comparison to 15 per cent of children outside of care. Around 22 per cent of young women who leave care go on to become teenage mothers, in contrast to a conception rate of 2.3 per cent for under 18s in England and Wales during 2014 (Office for National Statistics, 2016; Datta and others, 2017). Such and other statistics bring 
into question why more support is not offered to families prior to children being brought into care.

The relationship between entering care and reduced life chances for children and young people is complex and sometimes contested. Regarding educational achievements, for example, although children in care often lag far behind their peers, some commentators stress that mediating environmental, family or individual factors such as exposure to pre-care neglect or maltreatment can influence later learning (for example, Forrester and others, 2009). O'Higgins et al (2015: 5) systematic review of international empirical studies exploring the educational outcomes of children in care, nevertheless suggests that even when pre-care disadvantages are acknowledged many children 'do not appear to benefit academically from being in care' (see also Jackson, 2007). Sebba et al's (2015) small study of 26 teenagers across six local authorities (and who were in foster care for at least 12 months) suggests that at least some young people in care can improve their educational capabilities. This is more likely the longer a young person has been living in a stable care placement, as well as receiving consistent support, including from a social worker.

Despite some alleged difficulties establishing causal links to disadvantages, there are studies which suggest that fragmented service provision relating to marketisation intensifies further the association between being in care and reduced overall life chances. For example, in an independent review on behalf of the Prison Reform Trust (2017: 3), evidence from a participatory research project with children in care notes that whilst one per cent of children in England and two per cent in Wales were in care in 2016, around one half of a total of 1,000 children in custody at the time were or had previously been in care. The report quotes one child's personal experience, emphasizing the negative impact of entering a fragmented care system: 
"Since July 2013 I have been to 16 schools and I have been in 15 different placements all around the country...All of my offending has been whilst in care."

Young review panel member, aged 15, 25 June 2015

This report suggests that regular changes in who looks after young service users, where they live, are educated, and who offers practical or emotion support not uncommonly has a lasting impact upon the potential to engage in criminal behaviour. These trends persist in tandem with limited professional or formal welfare support often provided once leaving care, and the current failure of services and professionals to work together. Although more children do not enter the criminal justice system or enter custody (especially girls and young women), the report concludes that while in care there persists a lack of early intervention or preventative support available. Indeed, according to Ferguson $(2016,2017)$, contact with social workers for children and young people tends to now be extremely limited or non-existent beyond initial assessments. Indeed, contact is now more often dominated by brief, often highly emotive and challenging investigations or appearances at court.

In a recent report the Howard League for Penal Reform (2016: 3-8) detailed how police in England and Wales are now called out to children's residential homes thousands of times a year. In 2014-15 there were 10,299 call outs across 16 police forces. The report highlights that there is a 'tipping point' around the age of 13 for many children in care, at which stage societies sympathy is lost and 'rather than being helped, [children] are pushed into the criminal justice system'. Figures in the report from the Department of Education stress that a 13-15 years old child in care is now almost 20 times more likely to come into contact with the police than a child not in care and living with a family. In addition, the report argues that central government, local authorities, the police, and Ofsted are often failing to 'root out bad practices at the threequarters of England's 1,760 children's homes that are run by private companies'. 
Such outcomes counter core tenets of some established ethical perspectives. For example, as part of its fusion of Kantian perspectives and 'ready-to use kits of moral principles', bioethics highlights 'justice' as one of its four core principles. Whilst such professional ethics may often ignore or de-materialize structural inequality and poverty in favour of 'impersonal principles' that over generalise as part of all too convenient binary or reductive narratives (for example, Simpkin, 1979; Estes et al, 2003), bioethics does at least claim to promote fairness, equality, personal rights and a fair distribution of resources (Gillon, 1994; Zielinska, 2015). Such ideals are clearly compromised at regular intervals following market-based policies and street-level practices, which appear to influence significantly reduced life chances as relatively commonplace outcomes. Biehal and colleagues (2014: 10-18; 126-129) offer further evidence of disadvantage in their extensive survey of data drawn from 156 local authorities over three years in the UK. They report that a 'substantial minority' of children in care experience substantiated neglect or sometimes abuse at the hands of their formal carers within residential or foster care placements. In addition, within residential care, essential care plan reviews following a placement were 'rarely held', and there persisted considerable variation in terms of how staff were dealt with following an allegation within homes. However, the report notes that 'very few young people were removed from placement' following allegations, and, in general, 'life went on as before'. This report again highlighted some of the key problems generated by a fragmented system of care:

The lines of responsibility between local authorities for children placed out of authority could sometimes be confusing. In general terms, an allegation concerning a London child placed, for example, in the north of England would be managed by the host authority in which the placement is located. However, the extent to which the placing authority would be kept informed and would maintain records of the progress of this allegation appeared to be highly variable. In addition, the management of allegations 
between neighbouring local authorities was sometimes uncertain with respect to which areas took the lead on investigations.

The authors add that there were around 2,000-2,500 allegations per year made during their study, with between 450 to 550 substantiated. In general, confirmed allegations were dominated by physical or emotional abuse, with relatively fewer instances of neglect or sexual abuse. However, whether allegations were substantiated or not, a number of complex ethical and practical dilemmas and uncertainties were nearly always created for social workers following allegations. For example, difficulties would often remain in substantiating evidence, and subsequent risks persisted of either a child remaining in care or being removed from what may be a suitable and stable placement. Such moral complexity and procedural uncertainties invariably intensify much further - alongside necessary decision making and responsibilities - when service provision and ownership remains unclear or ever changing, and social work staff are transient or temporary employed.

\section{Ethical shortcomings to privatising the care of children and young people}

It has been argued that the privatisation and marketisation of social work generates a number of ethical problems regarding the care of children and young people. Three examples are provided, each developed from earlier discussions. First, the development of quasi-markets of social care have encouraged the commodification and objectification of many children, especially those with higher-level needs. This includes through the pervasive impact of market-based discourses, which ideologically reconstitute younger people as 'service users'. Here, complex political processes typically integrate a range of distinct yet interrelated discourses, including those which promote attributes such as (consumer-based) informed choice, autonomy and participation. Nevertheless, children as informed 'service users' will often lack the emotional or mental maturity, knowledge, and life experiences crucial to advocate and make decisions on 
their own behalf - including about their care - even if they are empowered by professionals to actively participate. Whilst social workers acting as case or care managers are intended to facilitate decision-making and advocate for service users, evidence suggests that this assumption is deeply flawed. This is not least due to numerous challenges faced by social workers, including their limited available resources or time to spend with children during overtly bureaucratic and risk averse casework (Howe, 1998; Parton, 2008; Petrie, 2010, 2015; Ferguson, 2016, 2017). Kemshall (2010: 1249) has highlighted that engagement and choices made by quasiconsumers within welfare markets generate a number of practical and ethical problems. For example, decision making is rarely rational, straight forward or based on simple decisions made between new opportunities and risks. Instead for "situated" social actors' decisions around choice or participation are much more nuanced and 'contingent on contextually based' experiences than in other consumer-based markets. In relation, at the level of agency, whilst potentially elevating 'empowerment' or some degrees of choice, participation reflects a different concept of 'citizenship' to that which traditionally operated under the Welfare State. In the latter ethical notions of justice integrating entitlements were often emphasised (Rawls 1971); whereas consumer-based endeavours understand support as being much more about promoting different traits (Carey, 2013). These include capacities for rational decision making, autonomy, responsibilities including self-care, which are each ethically challenging traits to impose on children or young people.

Second, one crucial argument made to support the extension of the private sector within quasimarkets of social care has remained that of making care services more flexible to better meet more diverse needs and promote better choices (for example, Harris, 2003; Cowden and Singh, 2007; Sellick, 2011). Among ties to other ethical frameworks, this perspective can be associated with elements of Kant's second formulation of the categorical imperative, that any person is not treated as a 'means to an end' (Simpkin, 1979). As we have seen, however, many children 
in care - including groups such as unaccompanied asylum seeking or disabled children - have limited choice regarding available services and tend to be especially vulnerable to objectification and social exclusion. This is due to market-centred outcomes such as local authorities reducing their responsibilities by increasingly moving children many miles away to other regions and local authorities. In relation, ever more business-centred managers within social services have become economically deterministic in their relative tendency to move children to less expensive authorities, and can be more eager to recruit less experienced and lower cost social workers. In addition, service providers can prioritise limiting resources and reducing cost in their decision making about providing care (Williams, 2012). Such evidence suggests that the social work business essentially promotes high degrees of means-to-an-end care, leading to increased user commodification and exclusion.

Finally, all key ethical perspectives or paradigms, including those embedded in professional codes of ethics, give precedence to varying degrees of fairness, equality or social justice. Such principles are perhaps more pronounced within the ethics of care, yet are also emphasised within aspects of deontological, utilitarian and bioethical frameworks. As discussed, there persists evidence that marketisation and privatisation within social work and care increases the likelihood of children and young people experiencing social exclusion and disadvantage whilst in care, and indeed often throughout their life course. Other commentators have gone further and argued that the child protection system now fails to adequately provide an appropriate response to the prevalence of child neglect, which is closely linked to structural factors such as poverty, inequality and social deprivation (for example, Daniel et al, 2014). In addition, concerns have been raised about the inefficiencies which market-based care generate, including a tendency for oligopolies to form, especially among corporate providers. This includes risks attached to financial opportunism or corruption linked to excessive commissioning and an underregulated contract culture (Scourfield, 2007; Davies, 2009; Petrie, 2015; Granter, 2019). 
Market-focused techniques of care also increasingly bind with other discourses to further disadvantage children. This includes a tendency for policy makers and some professionals to stress the seemingly flawed characteristics of families through casework, by incorporating service users into binary professional, logocentric, economically deterministic, biomedical and punitive/risk-averse discourses. Indeed, as Petrie (2010: 9) argues:

The 'child in need' has been constructed as a social problem with costs attached; for control, treatment or protection...Emphasis is placed on the cost-burden to society of what children do or do not do and how to change their behaviour. The current [market] discourse constructs children as 'bad', 'mad' or 'sad'. Children as individuals or in groups are dangerous, frightening or victims. Attention and resources are given to ways in which children can be controlled, because of 'criminal' behaviour, treated because of 'psychiatric disorder' or saved from child abuse.

In his influential thesis Politics, Aristotle (2017) argued that the State's very existence - including its moral responsibilities - went beyond any priority being given to economic concerns, exchanging goods, or averting physical harm. Its core role should, he argued, include a vital responsibility to provide a community or family of support so to ensure a free and independent life for all its citizens. When opportunities for later success in education, employment, or in maximising well-being or avoiding social exclusion become restricted within and following care, such basic ethical ideals appear increasingly to be lost within the social work business for many children and young people. It has been argued that privatisation remains central to many such inequitable outcomes, each of which carry important ethical implications.

\section{Note}


1. A quasi-market centres upon a split between a service purchaser and provider such as within a social care market. State social workers typically purchase services from a number of competing service providers.

\section{References}

Agnew, J., and Jorgensen, D. (2012) 'Informed consent: a study of the OR consenting process in New Zealand' Association of PeriOperative Registered Nurses Journal 95(6): 763-770.

Aristotle (2017) Politics: A New Translation Indianapolis, Hackett Publishing Company. Author (2018)

Baines, D. (2016) 'Care, Austerity and Resistance' in Williams, C. (ed) Social Work and the City Basingstoke, Palgrave Macmillan pp193-214.

Biehal, N., Cusworth, L., Wade, J., and Clarke, S. (2014) Keeping Children Safe: Allegations concerning the abuse or neglect of Children in Care York, University of York/NSPCC

British Broadcasting Corporation (2018) 'Kids used like 'pawns' in drug deals'. Retrieved from: $\quad$ https://www.bbc.co.uk/news/av/uk-wales-44132704/county-lines-children-used-likepawns-in-drug-gangs

Carey, M. (2003) 'Anatomy of a Care Manager' Work, Employment and Society 17(1): 121135.

Carey, M. and Foster, V.L. (2013) 'Social work, ideology, discourse and the limits of posthegemony’ Journal of Social Work 13(3): 248-266.

Carey, M. (2013) 'Some Ethical Doubts and possibilities regard Service Users Participation within Social Work' in Carey, M. and Green, L. (2013) Practical Social Work Ethics Aldershot, Ashgate. 
Coleman, N., and Harris, J. (2008) 'Calling Social Work' British Journal of Social Work 38 (3): $580-599$.

Cornes, M., Moriarty, J., Blendi-Mohota, S., Chittleburgh, T., Hessein, S., and Manthorpe (2010) 'Working for the Agency: The Role and Significance of Agency Working in the Social Care Workforce' London, University of London.

Clarke, J. (1996) 'After Social Work?’ in Parton, N. (ed) Social Theory, Social Change and Social Work Routledge, London.

Cowden, S. and Singh, G. (2007) 'The "User": Friend, Foe or Fetish? A Critical Exploration of User Involvement in Health and Social Care', Critical Social Policy 27(1): 5-23.

Daniel, B., Burgess, C., Whitfield, E., Derbyshire, D., \& Taylor, J. (2014). 'Noticing and helping the neglected child: messages from action on neglect'. Child Abuse Review, 23, 274-285.

Datta, J., Macdonald, G., Barlow, J., Barnes, J., and Elbourne, D. (2017) 'Challenges faced by young mothers with a care history and views of stakeholders about the potential for Group Family Nurse Partnership to support their needs' Children and Society 31(6): 463-474.

Davies, H. (2009) 'Ethics and Standards of Behaviour' in Loffler, E., and Bovair, T. (eds) Public Management and Governance Abringdon, Taylor and Francis

Department of Education (2017) 'Children looked after in England (including adoption), year ending 31 March 2017' [ https://www.gov.uk/government/uploads/system/uploads/attachment_data/file/556331/SFR41_2016_Text.pdf] accessed: 27/09/2018.

Estes, C.L., Biggs, S., \& Phillipson, C. (2003). Social theory, social policy and ageing: A critical introduction. Maidenhead: Open University Press. 
Fenwick, J. and McMillan, J. (2012) 'Public participation and public service modernisation: Learning from New Labour?' International Journal of Public Administration 35 (6): 367-378.

Ferguson, H. (2016) 'Professional helping as negotiation in motion: social work as work on the move' Applied Mobilities 1(2): 193-206

Ferguson, H. (2017) 'How children become invisible in child protection work: Findings from research into day-to-day practices’ British Journal of Social Work 47(4): 1007-1023.

Forrester, D., Goodman, K., Cocker, C., Binnie, C., and Jensch, G. (2009) 'What is the impact of public care on children's welfare? A review of research findings from England and Wales and their policy implications' Journal of Social Policy 38 (3): 439-456.

Foucault, M. (1991) Discipline and Punish: The Birth of the Prison London, Penguin.

Garrett, P. M. (2018) Welfare Words London, Sage.

Giddens, A. (1991) Modernity and Self-Identity: self and society in the late modern age. Cam bridge: Polity Press.

Gillon, R. (1994) 'Medical ethics: Four principles plus attention to scope' British Medical Journal 309 (6948): 184-188.

Granter, E. (2019) 'Critical Theory and Critical Social Work' in Webb, S. (ed) The Routledge Handbook of Critical Social Work' Oxton, Routledge. Pp61-72.

Harris, J. (2003) The Social Work Business London, Routledge. 
Holt, A. and Greenwood, G. (2017) 'Councils Spend Doubles on Social workers hired from agencies’ BBC News 1 November http://www.bbc.co.uk/news/education-39659252 accessed 3 December

Howard League for Penal Reform (2016) Criminal Care: Children's homes and Criminalising Children London, Howard League.

Howe, D. (1998) 'Relation-based thinking and Practice in Social Work' Journal of Social Work Practice 16(2): 45-56.

Humphris, R., and Sigona, N. (2017) 'Outsourcing the 'best interests' of Unaccompanied Asylum-Seeking Children in the Era of Austerity' Journal of Ethnic and Migration Studies Published Online $20^{\text {th }}$ December

Jackson, S. (2007) 'Progress at Last?' Adoption and Fostering 31(1): 3-5.

Jones, R. (2015) 'The End Game: The marketisation and Privatisation of children's social work and child protection' Critical Social Policy 35 (4): 447-469.

Jordan, B., and Drakeford, M. (2012) Social Work and Social Policy under Austerity Basingstoke, Palgrave Macmillan.

Jorgensen, K.J., Brodersen, J., Hartling, O.J., Nielsen, M., Gotzsche, P.C. (2009) 'Informed choice requires information about both benefits and harms' Journal of Medical Ethics 35 (4): 268-269.

Kemshall, H. (2010) 'Risk rationalities in contemporary social work policy and practice', British Journal of Social Work 40(4): 1247-1462.

Kerstein, S.J. (2009) 'Treating others merely as means' Utilitas 21(2): 163-180 
LaingBuisson - COBIC and CICADA (2016) The potential for developing the capacity and diversity of children's social care services in England [https://www.gov.uk/government/uploads/system/uploads/attachment_data/file/573035/LaingBuisson_report_December_2016.pdf] accessed: 16/09/2018.

Lash, S. (2007) 'Power after Hegemony: Cultural Studies in Mutation?' Theory, Culture, and Society. 24(3):55-78.

Lewis, G. (1998) 'Coming Apart at the Seams: The Crisis of the Welfare State', pp. 38-79 in G. Hughes and G. Lewis Unsettling Welfare: the Reconstruction of Social Policy. London: Routledge/Open University.

Lewis, J. and Glennerster, H. (1996) Implementing the New Community Care Buckingham, Open University Press

Morris, J. (2005). Children on the edge of care: Human rights and the Children Act. United Kingdom, London: Joseph Roundtree Foundation.

Office of National Statistics. (2016). Conceptions in England and Wales: 2014 Statistical Bulletin. Office of National Statistics: Newport.

O'Higgins, A., Sebba, J. and Luke, N. (2015) What is the Relationship between being in Care and the Educational outcomes of Children: An International Systematic Review Oxford, Rees Centre

Parton, N. (2008). Changes in the form of knowledge in social work: From the 'social' to the ‘informational'? British Journal of Social Work, 38(2), 253-269. 
Petrie, S. (2010) 'The 'Commodification' of 'Children in Need' in Welfare Markets: Implications for Managers' Social Work and Social Sciences Review 14(1): 9-26.

Petrie, S. (2015) "'Commodifying" Children: the Impact of Markets in Services for Children in the United Kingdom' International Journal of Child, Youth and Family Studies 6(2): 275294.

Prison Reform Trust (2017) In Care, Out of Trouble London, PRT

Rawls, J. (1971) A Theory of Justice Cambridge, Mass., Harvard University Press

Rose N. (1996) The Death of the Social? Re-figuring the territory of government. Economy and Society, 25(3): 327-356.

Richardson, H. (2017) 'Ninety children taken into care each day figures show' [http://www.bbc.co.uk/news/education-41581805]

Scourfield, P. (2007) 'Are there reasons to be worried about the 'Caretelisation' of Residential Care?' Critical Social Policy 27 (2): 155-180.

Sebba, J., Berridge, D., Luke, N., Fletcher, J., Bell, K., Strand, S., Thomas, S., Sinclair, I., and O’Higgins, A. (2015) The Educational Progress of Looked after Children: Linking Care and Education Data Rees Centre, University of Bristol. Bristol

Sellick, C. (2011). 'Commissioning permanent fostering placements from external providers: An exploration of current policy and practice'. British Journal of Social Work, 41, 449-466.

Simpkin, M. (1979) Trapped within Welfare London, Macmillan.

Thomas, C. (2007) Sociologies of Disability and Illness: Contested Ideas in Disability Studies and Medical Sociology Basingstoke, Palgrave MacMillan

Webb, S.A. (2006) Social Work in a Risk Society Basingstoke, Palgrave MacMillan. 
Williams, Z. (2012) The Shadow State: A Report about Outsourcing of Public Services London, Social Enterprise UK

Young, A., Carr, G., Hunt, R., McCracken, A.S., and Tattersall, H. (2006) 'Informed choice and deaf children: underpinning concepts and enduring challenges' The Journal of Deaf Studies and Deaf Education 11 (3): 322-336.

Young, A.M., Hunt, R., and Smith, C. (2009) The impact of integrated Children's services on the scope, delivery and quality of social care services for deaf children and families London, NCDS

Zielinska, A.C. (2015) 'Moral Principles and Ethics Committees: A Case against Bioethical Theories' Ethics and Social Welfare 9 (3): 269-279 
